\title{
COMPORTAMENTO DA TEMPERATURA DO AR SOB CONDIÇÕES DE CULTIVO EM AMBIENTE PROTEGIDO
}

\author{
Eduardo Texeira da Silva ${ }^{1}$ \\ Leandro Van Bem Byllardt ${ }^{2}$ \\ Siguifid Gomes ${ }^{2}$ \\ Geferson Davi Wolf ${ }^{2}$
}

\section{Resumo}

O objetivo deste trabalho foi o de analisar a variação da temperatura do ar dentro e fora de três estufas. O experimento foi conduzido na Fazenda Experimental do Cangüiri, pertencente à Universidade Federal do Paraná, localizada no município de Quatro Barras-PR. Foram utilizadas três estufas plásticas do tipo "Túnel Hermano", com estrutura em arco de PVC rígido formando um semicírculo, com área de $250 \mathrm{~m}^{2}$ ( $5 \mathrm{~m}$ largura por x $50 \mathrm{~m}$ comprimento), e altura de $2,5 \mathrm{~m}$, orientadas no sentido $\mathrm{NE} 49^{\circ} 07^{\prime}$ em relação ao comprimento, e dispostas lado a lado com espaçamento de 1,0 m. A Estufa 1 era coberta com filme transparente de baixa densidade, com $150 \mu \mathrm{m}$ de espessura; a Estufa 2 era coberta com filme leitoso de $150 \mu \mathrm{m}$ de espessura e a Estufa 3 com tela transparente, antigotejante, com estabilização anti-raios ultravioleta, de $200 \mu \mathrm{m}$ de espessura. A Estufa 2 foi a que apresentou melhores resultados para as condições da região, sendo sua tendência de linearidade no aumento da temperatura interna não limitante para seu emprego.

Palavras-chave: Estufas, Polietileno, Temperaturas.

\section{Abstract}

The objective of this work was to analyze the variation of the air temperature inside and outside three greenhouses. The experiment was conducted in the Cangüiri Experimental Station of the Federal University of Paraná, located in the city of Quatro Barras, PR. Three plastic high tunnel greenhouses were used, consisting of a semicircular PVC tubular frames with a total area of $250 \mathrm{~m}^{2}$ each $(5 \times 50$ X 2,5 m-WxLxH); oriented $49^{\circ} 07^{\prime} \mathrm{NE}$ in relation to their length, and set up as parallels 1,0 $\mathrm{m}$ apart. Greenhouse 1 was covered with low density transparent sheet, $(150 \mu \mathrm{m}$ thick); Greenhouse 2 with milky plastic sheet $(150 \mu \mathrm{m}$ thick) and Greenhouse 3 with a transparent, anti-drip shading screen film with UV-rays stabilization, (200 $\mu \mathrm{m}$ thick). Greenhouse 2, presented the best results for the local conditions and the tendency for linear increase in its internal temperature is not limiting.

Keywords: High tunnel, Greenhouse, Transparent film, Temperature.

1 Engo Agrícola (UFLA 1989), Mestre em Construções Rurais (UNICAMP 1992), Doutor em Construções Rurais e Ambientais (UNICAMP 1998), Professor adjunto Depto. de Solos da UFPR-SCA.

Rua dos Funcionários, 1540, Cabral, CEP 80.035-050, Curitiba, PR, eduardo@ufpr.br

2 Acadêmicos do Curso de Agronomia da UFPR/SCA - Estagiários do Depto. de Solos. 


\section{Introdução}

A produção de hortaliças no Brasil é denominada de cultivo protegido ou simplesmente estufa, tendo ou não controle ambiental. Existem duas possibilidades distintas quanto ao manejo do ambiente protegido. A primeira, na qual os produtores cultivam as hortaliças sob ambiente controlado; a segunda está vinculada aos produtores que cultivam, acreditando que basta construir uma estufa e recobri-la com um plástico e que as plantas terão condições para seu pleno desenvolvimento e produção. De acordo com Sentelhas \& Santos (1995), o emprego de estufas torna viável a produção de vegetais em épocas ou lugares cujas condições climáticas são críticas. Segundo Bliska \& Honório (1996), existem no mercado nacional a oferta de diversos materiais de cobertura para estufas, sendo que a entrada de produtos importados tende a beneficiar os usuários, não semente pelo aspecto econômico, mas também técnico. A umidade está diretamente relacionada à temperatura do ar. Os valores da umidade relativa do ar também são influenciados pela evapotranspiração. Em ambiente protegido, a umidade relativa (U. R.) durante a noite chega a 100\% e durante o dia, com a elevação da temperatura, a umidade relativa do ar diminui, podendo, nas épocas mais quentes do ano, reduzir a produção (Goto et. al., 1998). Apesar de inúmeras vantagens, as estufas comportam-se insatisfatoriamente do ponto de vista térmico, uma vez que durante o dia ocorrem temperaturas elevadas, que dificilmente são evitadas pela ventilação natural e, à noite, com freqüência, ocorrem temperaturas inferiores às críticas das plantas cultivadas. Considerando a umidade relativa do ar, Prados (1986) observou que os valores médios no interior da estufa de PEBD são similares aos observados a céu aberto, porém, analisando sua evolução durante o dia, verificou grandes variações, estas com valores elevados à noite (100\%) e muito baixos durante o dia (20\%).

\section{Material e métodos}

O experimento foi conduzido de 17/5/99 a 16/6/99, na Fazenda Experimental de Cangüiri, pertencente à Universidade Federal do Paraná, localizada no Município de Quatro Barras-PR, a uma latitude de $25^{\circ} 17^{\prime}$ e na longitude de $44^{\circ} 14^{\prime}$ Oeste, altitude de $950 \mathrm{~m}$. O clima da região é classificado, segundo Köeppen, como Cfb, que apresenta características de clima subtropical mesotérmico, super úmido, com verões frescos e geadas severas, demasiadamente freqüentes (média de 5 geadas/ano), sem estação seca. A temperatura média anual é de $16,5^{\circ} \mathrm{C}$, com média do mês mais quente e mais frio de $20,1{ }^{\circ} \mathrm{C}$ e $12,8^{\circ} \mathrm{C}$, respectivamente. $\mathrm{O}$ mês mais chuvoso é janeiro e o menos é agosto. As determinações foram realizadas no interior de três estufas plásticas do tipo "Túnel Hermano", com estrutura em arco PVC rígido, formando um semicírculo. Todas as estufas possuem área de $250 \mathrm{~m} 2(5 \times 50 \mathrm{~m})$, altura de $2,5 \mathrm{~m}$; orientadas no sentido NE $49^{\circ} 07^{\prime}$ em relação ao comprimento, dispostas lado a lado com espaçamento de 1,0 m entre as estufas. A primeira estufa coberta com filme transparente de baixa densidade, com 150 micra de espessura; a segunda com filme leitoso de 150 micra de espessura e a terceira com filme (tela) transparente, antigotejante, com estabilização anti-raios ultravioleta, de 200 micra de espessura. As três estufas possuem laterais móveis, permitindo total manuseio para abertura e fechamento. As estufas foram mantidas completamente fechadas durante a noite (das $18 \mathrm{~h}$ às $8 \mathrm{~h}$ ) e abertas lateral-mente até uma altura de aproximadamente $0,5 \mathrm{~m}$ da superfície do solo, somente nos dias ensolarados e/ou quentes (quando a temperatura do ar externo estivesse próximo de $20^{\circ} \mathrm{C}$, o que ocorria geralmente das $9 \mathrm{~h}$ às $16 \mathrm{~h}$ ). Em cada estufa existiam três canteiros nos quais estava sendo cultivada alface, esta irrigada aleatoriamente, por meio de um sistema de irrigação localizada. No interior das estufas, as temperaturas máximas, mínimas e atual do ar foram medidas das $8 \mathrm{~h}$ às $17 \mathrm{~h}$, com intervalos horários entre medições. Para medição das temperaturas, foram utilizados nove termômetros de coluna de mercúrio, com o corpo de plástico disposto da seguinte forma: três termômetros em cada canteiro, sendo um próximo à cultura, outro na altura média e outro próximo à cobertura, conforme poder ser visto na figura 1.

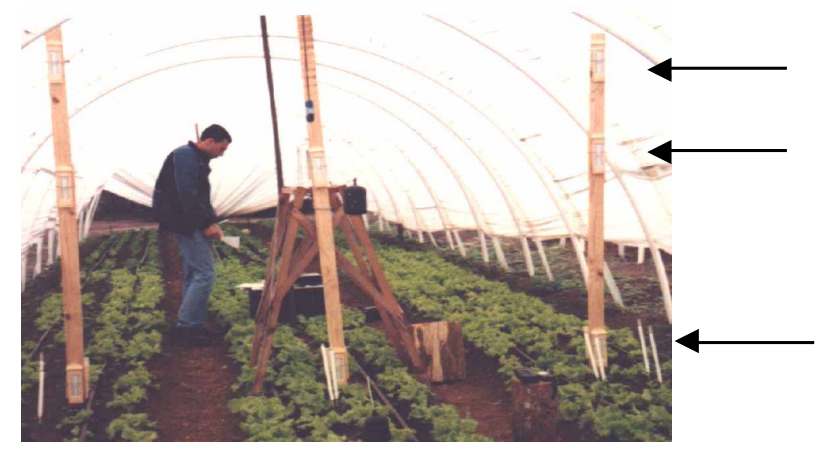

Figura 1 - Posicionamento dos termômetros instalados nas estufas. 


\section{Resultados e discussões}

Observou-se, por meio dos gráficos construídos com os dados medidos, que ocorreram algumas diferenças entre os valores verificados internamente nas estufas; as curvas que descrevem o comportamento das temperaturas máximas, atuais do ar e mínimas, em condições de ambiente protegido, apresentam similaridade quanto à forma e distribuição dos pontos, o que não acontece sob condições ambientais externas, onde as temperaturas são mais oscilatórias durante o dia. Ocorrem diferenças entre as temperaturas máximas das três estufas, sendo que a primeira apresentou pico de temperatura, às $14 \mathrm{~h}$, de $30 \mathrm{oC}$; a segunda, às $15 \mathrm{~h}$, de 26 oC e a terceira com 33 oC, às $14 \mathrm{~h}$. No gráfico da figura 2, pode-se observar que o aumento da temperatura durante o dia acontece de maneira suave, o que se acredita favorecer o desenvolvimento das culturas, pois não deve causar estresse à cultura. No gráfico da figura 3, pode-se observar que o aumento das temperaturas acontece durante o dia, seguindo a tendência de uma reta, com algumas oscilações, e atingindo pico máximo às $15 \mathrm{~h}$, a partir da qual torna-se descendente. No gráfico da figura 4, pode-se observar que o aumento da temperatura acontece de maneira muito semelhante ao da estufa 1.

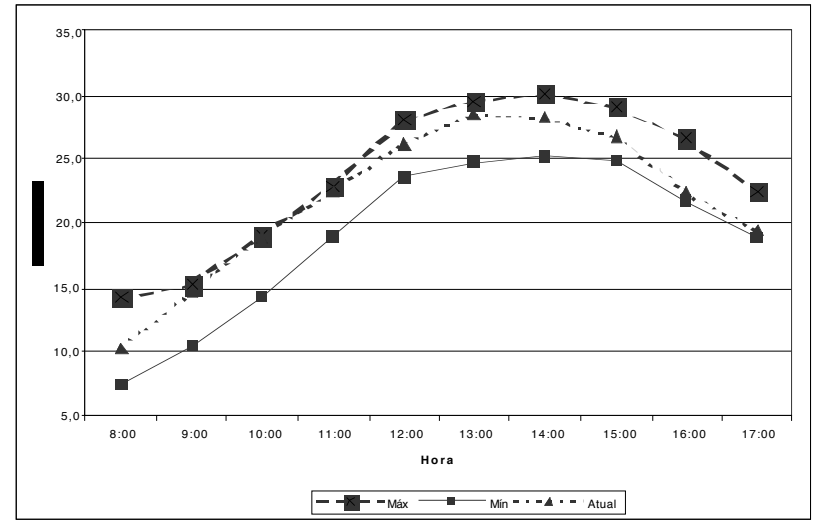

Figura 2 - Comportamento das temperaturas máximas, minimas e atuais na estufa 1

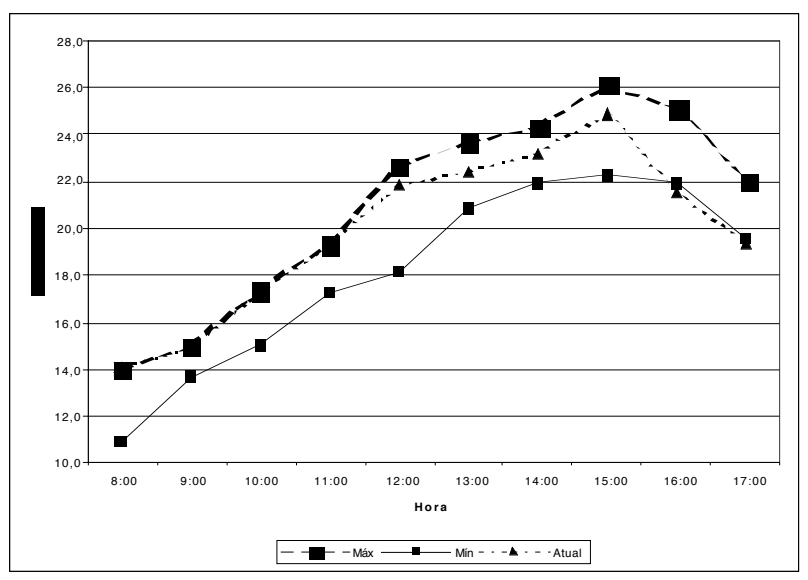

Figura 3 - Comportamentos das temperaturas máximas, minimas e atuais na estufa 2

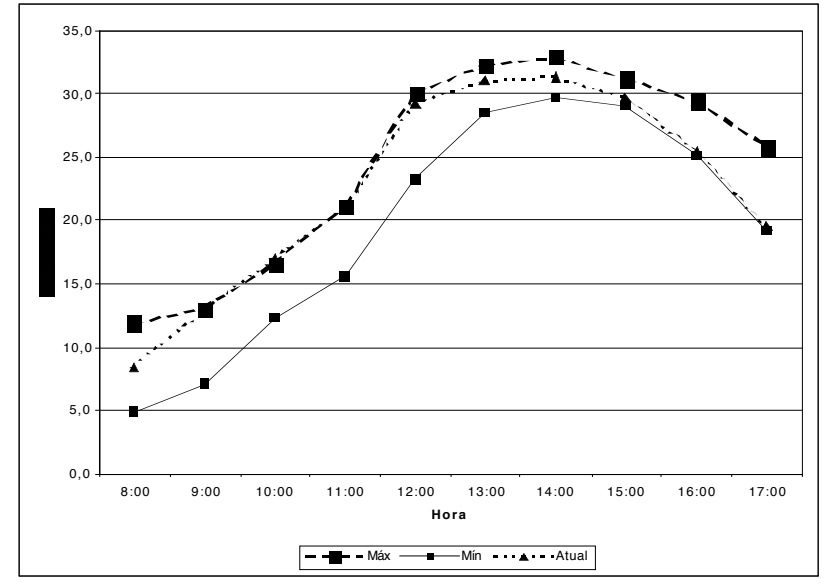

Figura 4-Comportamento das temperaturas máximas, minimas e atuais na estufa 3

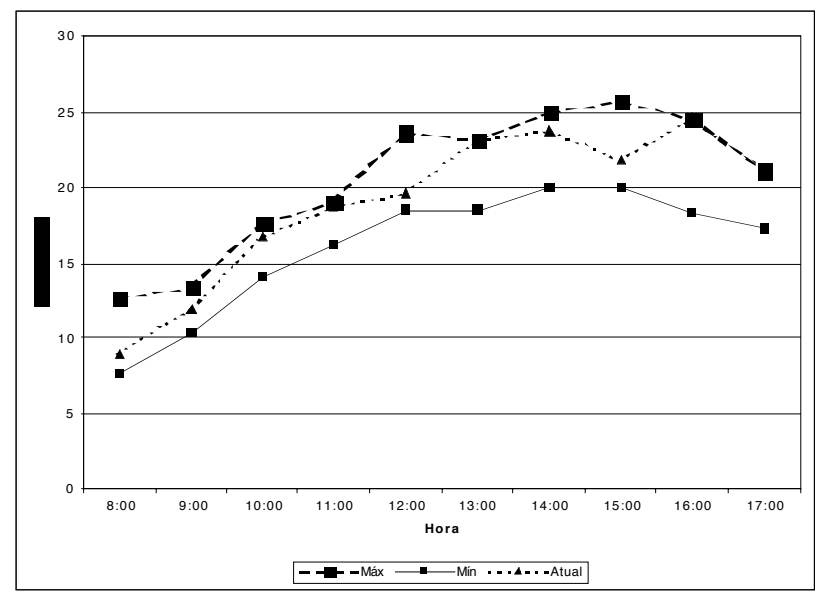

Figura 5-Temperaturas máximas, minimas e atuais do ar, próxima à estufa 1 


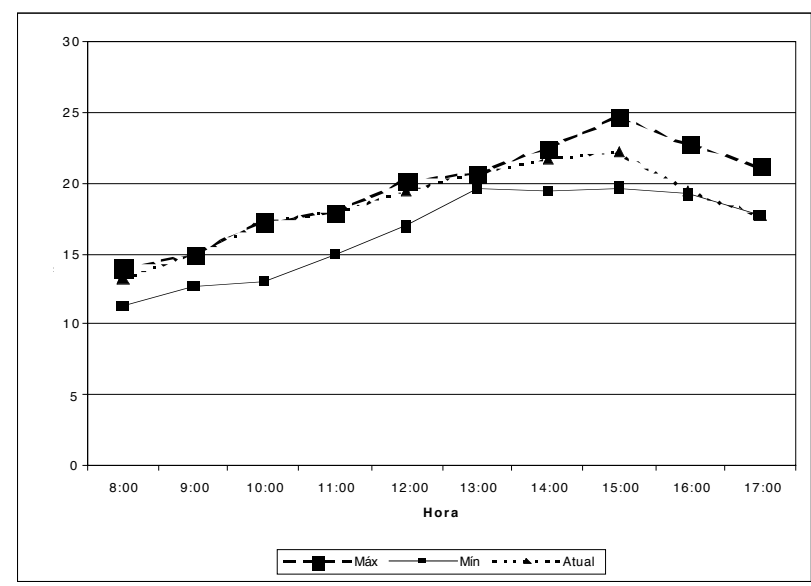

Figura 6-Temperaturas máximas, mínimas e atuais do ar, próxima à estufa 2

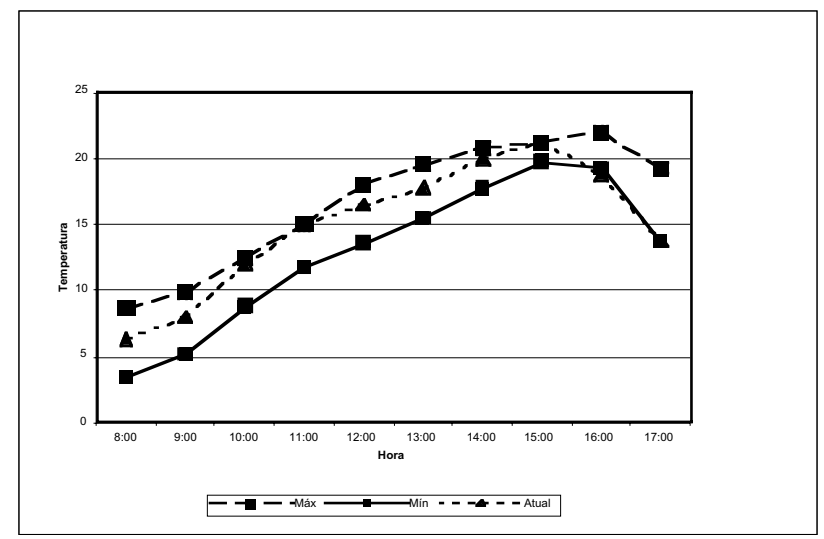

Figura 7-Temperaturas máximas, mínimas e atuais do ar, próxima à estufa 3

A estufa 2, com filme leitoso de 150 micra de espessura, foi a que apresentou melhor comportamento, ao manter a temperatura crescente de forma linear por mais tempo, não ultrapassando a $30{ }^{\circ} \mathrm{C}$, e por apresentar uma temperatura média mínima superior à limitante para a cultura da alface e, acima de tudo, apresentando uma curva mais linear, ou seja, o aumento da temperatura foi gradual, porém, menos agressivo. Em dias claros, observou-se que a temperatura do ar no interior da estufa esteve acima da verificada a céu aberto, ao longo do dia, apresentando diferenças que variaram entre 2 a $5{ }^{\circ} \mathrm{C}$. Em dias nublados, observou-se que as temperaturas internas e externas se aproximavam muito umas das outras, às vezes sem nenhuma variação. Para o caso das temperaturas mínimas entre as estufas, notou-se que a melhor retenção de calor aconteceu na estufa coberta com filme leitoso de 150 micras de espessura, na qual as temperaturas mí- nimas foram da ordem de $11^{\circ} \mathrm{C}$, o que é de fundamental importância, sendo um fator limitante ao cultivo em ambientes protegidos.

\section{Conclusões}

As estufas estudadas cobertas com filme de polietileno alteram acentuadamente os valores da temperatura máxima do ar. A nebulosidade determina o comportamento das temperaturas internas. Recomenda-se abrir as laterais quando a temperatura interna da estufa alcançar o limite fisiológico da cultura, observando sempre que a temperatura interna foi superior a externa, na ordem de 10 a $25 \%$. A estufa 2, coberta com filme leitoso, com 150 micra de espessura, foi a que apresentou melhores resultados para as condições da região; sua tendência de linearidade no aumento da temperatura não é limitante para seu emprego.

\section{Referências}

BLISCA JÚNIOR, A.; HONÓRIO, S. L. Cartilha tecnológica, plasticultura e estufa. Campinas: Editora. da Unicamp, 1996.

GOTO. R.; TIVELLI, W. Produção de hortaliças em ambientes protegidos: condições subtropicais. São Paulo: Fundação Editora da UNESP, 1998.

PRADOS, N. C. Contribucion al estúdio de los cultivos enarenados em Almeria: necessidades hídricas y extración del nutrientes del cultivo de tomate de crescimento indeterminado en abrigo de polietileno. Almeria, Espanha, 1996. 105 f. Tese (Doutorado em Fitotecnia) - Caja Rural Provincial, Almeria.

SENTELHAS, C.S.; SANTOS, A. O. Cultivo Protegido: Aspectos microclimáticos. Revista Brasileira de Floricultura e Plantas Ornamentais. v.1, n.2, p.108-115, 1995.
Recebido 10/12/00 Aprovado 10/02/01 